\title{
Providing Hearing Education and Resources for Underserved Populations (HEAR-UP) in our Local Neighborhoods
}

\author{
Kathleen Costigan Coyan, Au.D. ${ }^{1}$ and Elaine Mormer, Ph.D. ${ }^{2}$
}

\section{ABSTRACT}

Healthcare services in the United States are difficult to access for at least $10 \%$ of our population. Moreover, hearing healthcare services, including hearing aids, are largely inaccessible even for those individuals who may have health insurance and access to healthcare. Humanitarian audiology has been recognized as a means of supplying hearing services and devices to underserved populations around the globe. However, little has been publicized about humanitarian audiology projects taking place in local communities within the United States. This article describes one such project that has been in place in Pittsburgh, PA, for the past 4 years. This service results from collaboration across a collection of healthcare, community service, charitable, and educational organizations. The resources necessary to create similarly sourced services in other U.S. locations are described. Challenges and solutions for this local form of humanitarian audiology are discussed.

KEYWORDS: underserved, Federally Qualified Health Clinic (FOHC), free clinic, hearing health access

Humanitarian audiology, to many people, brings to mind images of an overseas mission. However, it is not necessary to leave your community to provide humanitarian services. It is estimated that as many as 30 million Americans lack basic health insurance coverage. ${ }^{1}$ This amounts to one in ten Americans who are not able to access necessary care. Additionally, individuals who are noncitizens have a shorter duration of residence in the United States, lower levels of English proficiency, and lower probability of access to a consistent source of care. ${ }^{2}$ The working poor, uninsured, underinsured, refugees, and immigrants often rely on free clinics to bridge the gap in healthcare. In short, there are vulnerable people in the local community. Table 1 displays data on individuals in the United States living

${ }^{1}$ Audiology and Hearing Aids, University of Pittsburgh Medical Center, Pittsburgh, Pennsylvania; ${ }^{2}$ Department of Communication Science and Disorders, University of Pittsburgh, Pittsburgh, Pennsylvania.

Address for correspondence: Kathleen Costigan Coyan, Au.D., Audiology and Hearing Aids, University of Pittsburgh Medical Center, 9104 Babcock Blvd Ste 3112, Pittsburgh, PA 15237 (e-mail: costigankt@upmc.edu).

Humanitarian Audiology; Guest Editor, Steven P. Smith, Au.D.

Semin Hear 2020;41:124-132. Copyright (C) 2020 by Thieme Medical Publishers, Inc., 333 Seventh Avenue, New York, NY 10001, USA. Tel: +1(212) 760-0888. DOI: https://doi.org/10.1055/s-0040-1708509.

ISSN 0734-0451. 
Table 1 Number of People Living Below Poverty Level, Uninsured, and with Immigrant Status in Highly Populated States in America, in 2017

\begin{tabular}{lllll}
\hline State & Below poverty level & No. of uninsured & Uninsured (\%) & Immigrant \\
\hline Pennsylvania & $13.6 \%$ & 910,205 & $11.90 \%$ & 842,000 \\
New York & $15.9 \%$ & $1,521,235$ & $12.40 \%$ & $4,491,000$ \\
Florida & $16.6 \%$ & $2,809,126$ & $23.90 \%$ & $1,801,000$ \\
Washington & $13.2 \%$ & 556,886 & $12.70 \%$ & 987,000 \\
Illinois & $14.3 \%$ & $1,109,614$ & $14.00 \%$ & $1,801,000$ \\
Texas & $17.2 \%$ & $4,201,804$ & $25.80 \%$ & $4,622,000$ \\
California & $16.4 \%$ & $4,168,408$ & $17.30 \%$ & $10,581,000$ \\
\hline
\end{tabular}

below the poverty level, those who are uninsured, and those who are immigrants, within heavily populated states. These numbers provide a compelling argument to consider serving our local communities when planning humanitarian missions.

\section{RESOURCES IN THE UNITED STATES FOR FREE AND LOW-COST HEALTH SERVICES}

The National Association of Free and Charitable Clinics (NACF) was established in 2001 to assist those who fall through the cracks in our current healthcare system. There are approximately 1,400 free clinics in the United States, some of which have been in operation since the 1960s. Together, these clinics service an estimated 1.8 million people per year. ${ }^{3,4}$ Table 2 shows examples of the number of existing free clinics in a sampling of cities across the United States.

Despite the wide availability of these clinics, specialty care can be expensive, difficult to access, and is often not available at these sites. This is particularly true of hearing healthcare, as the high cost of hearing aids renders them out of reach for members of vulnerable populations.

Table 2 Number of Free Clinics Existing in a Sampling of U.S. Cities 5

\begin{tabular}{ll}
\hline Location & Existing free clinics \\
\hline Pittsburgh, PA & 41 \\
Buffalo, NY & 11 \\
Gainesville, FL & 12 \\
Seattle, WA & 52 \\
Chicago, IL & 108 \\
Dallas, TX & 20 \\
San Diego, CA & 38 \\
\hline
\end{tabular}

Federally Qualified Health Clinics (FQHCs) offer another option for those in need of help accessing medical care. These are community-based centers that receive government funding through the Health Resources and Services Administration (HRSA) with the goal of providing care in underserved areas. These centers must meet strict requirements to qualify for funding and must provide care on a sliding scale based on a patient's ability to pay. Typically, an FQHC offers comprehensive services that include both preventative and primary care, along with support services and rarely are subspecialty services available. There are approximately 1,400 FQHCs spread across all 50 states and U.S. territories and services are provided without regard to patients' citizenship or insurance status. ${ }^{6}$

\section{THE NEED FOR HEARING CARE IN OUR UNDERSERVED POPULATION}

Members of vulnerable groups have a particular need for hearing care. According to Emmett and Francis, hearing loss is associated with low educational attainment, low income, unemployment, and underemployment. Even mild losses have been found to impact speech/language development and school performance in childhood. Using data from the National Health and Nutrition Examination Survey (NHANES 1999-2002), Emmett and Francis demonstrated associations between low socioeconomic status and intrauterine growth restriction, which places children at increased risk of complications involving hearing loss and cognitive delays. Adverse effects can continue into adulthood limiting options for higher education. Additionally, the NHANES data showed that individuals with hearing loss had nearly two times the odds 
of unemployment, an annual income less than $\$ 20,000$, and a decreased likelihood for completing high school. The exact relationship between low educational attainment and hearing loss is unclear. It can be difficult to determine whether the hearing loss contributes to a lack of higher education, or if those who have attained less education are more likely to pursue types of work that increase noise exposure. In any case, the conclusion is that hearing loss and socioeconomic status are related. ${ }^{7}$ In short, many of the people who can particularly benefit from hearing care are unable to afford it, particularly those who need to hear to access English language learning.

The comorbidities of untreated hearing loss have received much attention in recent scientific journals and popular press. Patients with hearing loss have been found at greater risk for depression, isolation, and hospitalization; poorer adherence to treatment recommendations; more preventable adverse medical events and accidental injury; as well as accelerated cognitive decline and brain atrophy. ${ }^{8,9}$ Furthermore, a recent University of Michigan study showed that adults younger than 50 years with hearing loss, even after adjusting for differences in socioeconomic status and mental health, were more likely to engage in substance abuse. ${ }^{10}$ Researchers suggested that the difference could be related in part to the marginalizing effects of hearing loss. 5 These data are compelling in terms of illustrating the need for accessible audiology services across geographic and socioeconomic lines.

\section{THE CRITICAL COLLABORATION LEADING TO HEAR-UP}

\section{Personnel and Sites}

Students and professionals often volunteer time to conduct hearing screening programs. However, once identified, members of vulnerable populations have very few options for follow-up evaluation or treatment. Fortunately, there are organizations that provide a framework, and funding, for students and professionals interested in serving these groups. One such organization is the Albert Schweitzer Fellowship and is geared toward student involvement. This national nonprofit organization supports graduate students in the pursuit of high impact, volunteer community services, while facilitating the mindful development of leadership skills. Interested students apply for funded fellowships via a rigorous competitive process, managed through one of 15 Schweitzer Fellowship Program chapters across the United States. Those who are accepted into the Schweitzer Fellowship program are guided through the process of developing and implementing a health-focused service project, addressing needs in under-resourced locations. Active academic and clinical mentoring plays a major role in the success of each Schweitzer project. Our local hearing care service began with a University of Pittsburgh AuD student who successfully applied to become a Schweitzer Fellow. Her goal for the required community service project was to provide audiology services and hearing aids to underserved individuals, locally. ${ }^{11}$ This Schweitzer audiology project began as an offshoot of healthcare services provided at an existing free clinic.

The introduction of audiology into the Pittsburgh Schweitzer Fellowship program resulted in the Hearing Education and Resources for Underserved Populations (HEAR-UP) project. This project, in collaboration with our University of Pittsburgh Medical Center Audiology department, was designed to offer diagnostic testing, counseling, and hearing aid dispensing as needed. Services were introduced first at the Birmingham Free Clinic, operating in an urban neighborhood on the Southside of Pittsburgh. This clinic services patients with no health insurance, many of who are homeless, undocumented, or otherwise impoverished. Scheduling, communication, and transportation challenges abound in this group of patients, such that services need to be delivered all in one appointment, with no cost to patients.

In 2017, we duplicated the HEAR-UP program at an existing FQHC, the Squirrel Hill Health Center (SHHC), in another neighborhood of the city of Pittsburgh. This center services a broad array of under-resourced patients and is heavily accessed by immigrant and refugee families.

At each of the HEAR-UP sites, audiology services are largely managed by students, under the clinical supervision of the authors. Services are offered one time per month at each site, 
throughout the year. Given the heavy workload involved in the management of equipment, space, and scheduling issues, students now apply for Schweitzer Fellowship project in pairs, so that the manpower is doubled at each site. It is efficient to offer the services at one site in the morning and the other in the afternoon/evening, on the same day of the month. HEAR-UP is currently in the fourth year of existence and it is clear that this experience provides an exceptional educational opportunity for students, while serving a critical need in the community.

\section{Funding for Equipment and Supplies}

Funding for equipment and hearing aids is procured from a foundation associated with the Eye and Ear Institute at the University of Pittsburgh Medical Center. Donations to the foundation provide a portable audiometer/tympanometer, Insta-Mold products, hearing aids, and programming hardware. Cost of hearing aids has been reduced through negotiation with one of the hearing aid manufacturers who was informed of the overall goal of the project. An additional challenge involved in a once-amonth portable clinic, at two different sites, is that all clinic equipment and materials must be removed when the clinic day is over. The equipment and supplies are housed in a large, wheeled suitcase. In addition to portable diagnostic equipment, this suitcase provides storage for multiple pairs of hearing aids, tubing, domes, tools, Insta-Mold materials, a NoahLink Wireless programmer, lighted curettes, amplifiers, and batteries, along with all of the usual tools and disposable supplies necessary for hearing aid dispensing. The Schweitzer Fellow students are responsible to monitor the inventory of hearing aids and supplies on an ongoing basis. Additionally, these students manage the strategic packing and unpacking of the suitcase, as well as set-up and break-down of the clinic area for each sites' monthly clinic hours.

\section{Logistics of Providing HEAR-UP Services}

As noted, the logistics of running monthly clinics are primarily managed by two Schweitzer Fellow students and one supervising audiologist at each site. During clinic hours, an all-handson-deck approach is necessary to effectively manage the patient's schedule. The schedule at the Birmingham site allows for appointments in 15-minute blocks, with as many as nine patients scheduled in a morning. These appointments range from regular follow-ups to hearing tests. If it is found that a patient could benefit from hearing aids, the fitting is performed at the same appointment. This requires making Insta-Mold earmolds, when needed. As such, two rooms are warranted to stay on schedule. For the sake of consistency, only BTE hearing aids from one manufacturer, with size 13 batteries, are dispensed.

The SHHC site follows a similar pattern, though most of the referrals at that site are for hearing aid fittings. In these cases, a completed audiologic evaluation and report is already available in the patient's medical record, on site as most of the patients have had an evaluation completed at the University Medical Center. Appointments at the SHHC are scheduled in 30-minute slots and, similar to the Birmingham site, and two rooms are used at one time to manage the schedule.

At both sites, patients who are given hearing aids are scheduled to return the next month for follow-up. The attendance rate for first follow-up appointments is nearly $100 \%$ at both sites. If the patient has reported successful use of the aid, verified by data logging, the International Outcome Inventory for Hearing Aids (IOI-HA) ${ }^{12}$ is completed at the first follow-up appointment. At the time of the fitting, each patient is given a box of size 13 batteries. Batteries are available for pickup at the front desk as needed, and the patient is instructed that when the battery supply runs out, it is a good idea to come for a routine follow-up appointment. The follow-up rate beyond the first post fitting appointment is considerably lower.

\section{Eligibility}

A management team is utilized at each clinic site to assure that the intended target population is being served. The Birmingham Free Clinic is designed specifically for patients without insurance; however, the audiology 
service has been known to make exceptions. The hearing aid clinic is intended as a service of last resort; therefore, patients who qualify for hearing aids through other sources are not eligible at the sites. Patients who cannot afford the application fees for other funded programs can be serviced through HEARUP.

At the SHHC, eligibility for hearing aid services is strictly determined by intake staff at the clinic, based on family income levels. Specifically, patients at this clinic can qualify for hearing aids if their income is below 200\% of the poverty level.

\section{Sustainability}

As with any charitable clinic, sustainability is a priority. Sustainability is highly dependent on continuing collaboration across all of the organizations who contribute to this mission. Table 3 lists the varied sources and types of contributions resulting in this collaborative project and illustrates the complexity of this endeavor. After the contributions from each party were agreed upon and secured, a considerable amount of ongoing relationship building and communication has been necessary for sustainability.

Student involvement in the Schweitzer Fellowship is not necessarily required to provide services at these clinics; however, collaboration with this organization has been very worthwhile. The Fellowship requires students to spend time at monthly meetings and to reflect upon challenges faced by the underserved population. Each new pair of fellows is required to add a new component to the project, and existing fellows cultivate an interest among other students in an effort that future student cohorts will sustain interest.

\section{Challenges}

Some of the challenges arising in this endeavor have been described earlier. As in any mobile or temporary clinic, there is a limit to the space and time that can be devoted, in addition to what can physically be carried. Similarly, careful allocation of funding is evaluated for the most critical needs. This poses the immediate challenge to use of best practices in these clinics. For example, limited resources in funds, space, and time preclude the use of a probe microphone system for hearing aid verification. During initial fittings, first fit settings are used and adjustments are made based on subjective feedback from the patient (often via a face-to-face or remote language interpreter). Due to frequent communication barriers, there may be no more than the intensity of the patient's smile to guide these adjustments. Anecdotally

Table 3 Sources and Types of Support Contributing to the Pittsburgh HEAR-UP Program

\begin{tabular}{|c|c|c|}
\hline $\begin{array}{l}\text { Type of } \\
\text { agency/institution }\end{array}$ & Name of agency/institution & Type of support \\
\hline $\begin{array}{l}\text { Community service } \\
\text { organization }\end{array}$ & $\begin{array}{l}\text { Pittsburgh Schweitzer } \\
\text { Fellowship Program }\end{array}$ & Funds student fellows' participation \\
\hline Audiology center & UPMC Audiology & $\begin{array}{l}\text { Personnel for mentoring and supervision; } \\
\text { administrative and computer support; clinical materials; } \\
\text { computer and technical support; access } \\
\text { to foundation funding }\end{array}$ \\
\hline $\begin{array}{l}\text { Charitable } \\
\text { foundation }\end{array}$ & $\begin{array}{l}\text { UPMC Eye and } \\
\text { Ear Foundation }\end{array}$ & Funds equipment, supplies, and hearing aids \\
\hline $\begin{array}{l}\text { University with } \\
\text { AuD program }\end{array}$ & University of Pittsburgh & Student recruitment; mentoring; clinical supervision \\
\hline $\begin{array}{l}\text { Free or charitable } \\
\text { health clinic }\end{array}$ & Birmingham Free Clinic & $\begin{array}{l}\text { Site integration within existing clinic; } \\
\text { scheduling of appointments and follow-up; } \\
\text { eligibility determination }\end{array}$ \\
\hline $\begin{array}{l}\text { Federally qualified } \\
\text { health center }\end{array}$ & Squirrel Hill Health Center & $\begin{array}{l}\text { Site integration within existing clinic; } \\
\text { scheduling of appointments and follow-up; } \\
\text { eligibility determination }\end{array}$ \\
\hline
\end{tabular}


this is referred to as the Smile Scale when initially determining the adequacy of fit. While this creates many ethical questions regarding verifying the hearing aid fitting by the intensity of the patient's smile, it is done with the best intentions, with an eye on patient satisfaction. As in any humanitarian audiology setting, the goal is to dispense hearing aids that will be worn consistently. Data logging has proven to be the most objective outcome utilized in follow-up appointments.

As mentioned earlier, the follow-up rate after 6 months is low and the no-show rate for these appointments is high. Many members of the patient population move frequently and do not have consistently working phone numbers. Appointments are frequently canceled due to lack of transportation. In 2018 the Birmingham clinic no-show appointment rate was $30 \%$.

Patients' cultural norms and language barriers are challenges that have required careful consideration. At the Birmingham clinic, there is a Spanish language interpreter on site; however, there is a diverse population speaking many languages. Family members and friends often serve as translators; however, the message frequently gets lost, or otherwise the family member does not include the patient in the discussion. Test instructions can be particularly challenging when an interpreter is not available, and reinstruction is needed multiple times. Access to a remote telephone translation service is possible but expensive, and it is impractical to keep the translator on the line while testing is completed. In one particular case, a child with special needs who spoke only Portuguese needed an evaluation. Access to a Portuguese inter- preter was not available, and the family felt that the use of a Spanish interpreter may be sufficient. In this case, it was determined that the path of least resistance was the memorization of test instructions in Portuguese instead of attempting to use a language that may be similar to the patient's native language. This year, written test instructions in multiple languages have been gathered. To date, a list representing 16 languages has been obtained. Fig. 1 is an example of one such set of test instructions.

Interestingly, it was thought that this population would lose hearing aids at a higher rate than other groups; however, this has not been the case. To date, only four hearing aids have required replacement for two individual patients, due to being lost or stolen. Having fit over 40 patients with hearing aids at Birmingham alone since the start of this project, this is not considered to be significant.

\section{IMPACT}

In 2018, the Birmingham clinic saw 34 appointments including 19 new patients; 18 hearing aids were dispensed for nine patients, five of who had disabling hearing loss as defined by the World Health Organization. The average age of patients seen in 2018 was 60.6 years. In regard to outcomes from the hearing aid fittings, patient data from the IOI-HA have shown very favorable responses. Of 28 patients fit at the SHHC site over the past year, all indicated that their enjoyment of life was either quite a lot better or very much better after at least 1 month of hearing aid use. In response to the question "Think again about the situation where you most wanted to hear better. When you use your

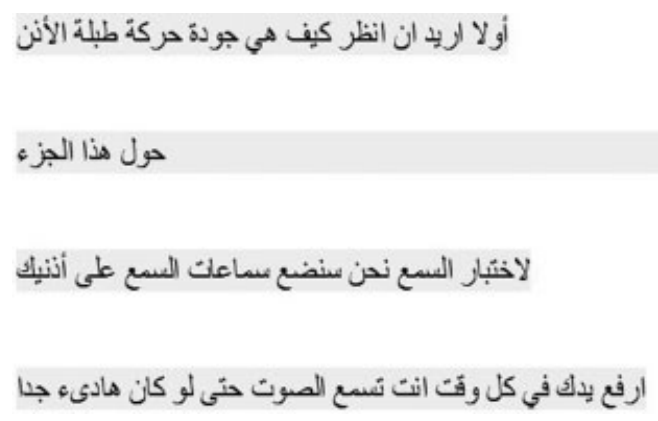

Figure 1 Audiometric test instructions in Arabic. 
new hearing aids, how much difficulty do you still have in that situation?, all responses were either no difficulty or slight difficulty, excepting two responses of moderate difficulty. Subjectively, the patients and their families consistently express gratitude for hearing services. Perhaps the most unfortunate outcome of this service has been the wait list time, which is now somewhere between 8 and 12 months for an initial hearing aid fitting appointment at Squirrel Hill.

We have felt very fortunate to be able to extend hearing healthcare to a population we care about. The impact on our individual patients has been profound. This population faces challenges which are foreign to most of us. Care has been provided to homeless individuals who come because they sleep in dangerous places, refugees who developed tinnitus after narrowly escaping explosions, and a terminally ill patient who wanted to engage during the time he had left. One of our graduated Schweitzer Fellows shared the following experiences:

One patient at SHHC had a moderate to profound hearing loss and reported he could not hear his granddaughter's voice. He said his goal was to hear her at Christmas dinner, which was coming up in a few weeks. We fit him with hearing aids, and he was immediately so happy to be able to hear us better. When we saw him for his followup he started crying because he said he could finally hear his granddaughter and that he once again was actively engaged in conversation with his family on Christmas day. $\mathrm{He}$ was extremely grateful for our services!

I remember that one patient at Birmingham said he was having anxiety because he could not hear his fire alarm but could not afford hearing aids to help with this. When we saw him again, he reported that he tried out his alarm and was now able to hear it, which gave him more peace of mind.

We saw a patient at $\mathrm{SHHC}$ who came in with his daughter. His daughter was in school to become a dentist. He worked as a janitor and said he was having difficulty hearing his coworkers, making it hard to perform his job adequately. His job was very important to him, especially because he was trying to help his daughter through school. After we fit him with aids, he said he was able to hear his coworkers once again and was satisfied with his work performance once again.

Another student reflected on her experience as follows:

Our experiences with patients at Birmingham Free Clinic have truly been an impactful reminder of how the services provided there continue to change lives for the better. One such encounter was that of my partner and I meeting a middle-aged woman with hearing loss for her first appointment. At first glance, she seemed only mildly frustrated with the effects that hearing loss had in her life when it came to communicating and feeling connected to the world around her. However, as she continued to tell us her story, we saw how deeply these frustrations ran and what emotional and social consequences she had faced as a result. Upon completing her hearing test and showing her the results, she was shocked to learn that her hearing loss was clinically of a mild degree because the difficulties she had been experiencing in everyday life were more severe. Following this evaluation, we fit her with hearing aids and were very touched by her reaction. She was overwhelmed with emotion and teared up as she started to tell us how long this hearing loss had gotten in the way of communication with loved ones and even simple interactions with strangers in her daily life. She kept asking us to speak at a comfortable level and even got up, walking around the space, in awe that she could hear us without having to strain or ask for multiple repetitions. As she thanked us profusely and made her way out with a visibly positive change in her demeanor, my project partner and I were reminded of the fact that a clinical change in hearing that only seems mild to the onlooker translates to a very different degree out in the world. This interaction among many continues to inspire us to truly listen to our patients when 
Table 4 Resources to Create Local Humanitarian Audiology Services

\begin{tabular}{ll}
\hline Action & Information access \\
\hline $\begin{array}{l}\text { Locate federally qualified } \\
\text { health centers }\end{array}$ & https://bphc.hrsa.gov/about/index.html \\
Locate Schweitzer & https://schweitzerfellowship.org/ \\
Fellowship programs & \\
Find a clinic belonging to the & https://www.nafcclinics.org/find-clinic?gclid=CjwKCAjw3c_tBRA4EiwAl \\
National Association & Cs8CnRKUV3VX5btqHZ3riiVIGnl_mvhCNGsN5sej5R8Sa2j \\
of Free and Charitable Clinics & ML1NYJq14RoCMxYQAvD_BwE \\
Seek help from foundations & https://Www.hearing.org/hearingorg/document-server/? \\
providing financial & cfp=hearingorg/assets/File/public/HIA_Financial-Assistance-Guide.pdf \\
assistance for hearing aids & \\
\hline
\end{tabular}

they voice concerns instead of only relying on the clinical data, and this will shape us into the best audiologists we can be for those we serve.

\section{CONCLUSION}

A significant portion of individuals living in the United States do not have access to hearing healthcare services. These individuals, many of who are struggling to learn English as a second language, are at a considerable disadvantage when trying to achieve an improved quality of life. With carefully choreographed collaboration across existing educational, charitable, medical, and community service organizations, it is possible to create humanitarian audiology programs for this population, in our local neighborhoods. The HEAR-UP program serves as a model of this formula and could be recreated at several locations across the United States. Table 4 provides resources and access information so that readers can locate possible local partners in this pursuit.

\section{CONFLICT OF INTEREST}

None declared.

\section{ACKNOWLEDGMENTS}

The authors acknowledge the significant contributions to the HEAR-UP project by the UPMC Center for Audiology and Hearing Aids, under the direction of Dr. Catherine
Palmer. The HEAR-UP project was founded by former Schweitzer Fellow, Dr. Rachel Fryatt. Student reflections for this article were contributed by University of Pittsburgh AuD students, and current Schweitzer Fellows, Hannah Famili and Leila Oyekola.

\section{REFERENCES}

1. Henry J. Kaiser Foundation. Key Facts about the Uninsured Population. Available at: https://www. $\mathrm{kff}$.org/uninsured/fact-sheet/key-facts-about-theuninsured-population/. Published December 7, 2018. Accessed February 20, 2020

2. Lee $S$, Choi S. Disparities in access to health care among non-citizens in the United States. Health Sociol Rev 2009;18(03):307-320

3. Wertz AP, Mannarelli G, Shuman AG, McKean EL. Comprehensive hearing aid intervention at a free subspecialty clinic. JAMA Otolaryngol Head Neck Surg 2017;143(09):876-880

4. Kornak J. A hand up: connecting low-income patients with hearing aids: low-income people with hearing loss often face additional obstacles to everything from employment to health care and hearing aids. One organization is trying to help. ASHA Lead 2019;24(01):20-22

5. Free Clinics: Free Medical Clinics: Free Health Clinics. ( n.d. ). Available at: http://www.freeclinics.com/. Accessed February 20, 2020

6. National Association of Community Health Centers. Available at: http://www.nachc.org/about/ about-our-health-centers/. Published 2019. Accessed February 20, 2020

7. Emmett SD, Francis HW. The socioeconomic impact of hearing loss in U.S. adults. Otol Neurotol 2015;36(03):545-550 
8. Jung D, Bhattacharyya N. Association of hearing loss with decreased employment and income among adults in the United States. Ann Otol Rhinol Laryngol 2012;121(12):771-775

9. Genther DJ, Frick KD, Chen D, Betz J, Lin FR. Association of hearing loss with hospitalization and burden of disease in older adults. JAMA 2013;309 (22):2322-2324

10. McKee MM, Meade MA, Zazove P, Stewart HJ, Jannausch ML, Ilgen MA. The relationship between hearing loss and substance use disorders among adults in the U.S. Am J Prev Med 2019; 56(04):586-590

11. Fryatt R. The Schweitzer Fellowship: Making a Difference in Local Communities. The Hearing Journal. Wolters Kluwer Health, Inc; 2017. Available at: https://journals.lww.com/thehearingjournal/blog/onlinefirst/pages/post.aspx?PostID=18. Accessed February 20, 2020

12. Cox RM, Stephens D, Kramer SE. Translations of the International Outcome inventory for Hearing Aids (IOI-HA). Int J Audiol 2002;41(01):3-26 